\title{
LAS ALTERIDADES DE LA MODERNIDAD
}

\section{Buenos Aires 1880-1910}

\section{Sandra Gayol}

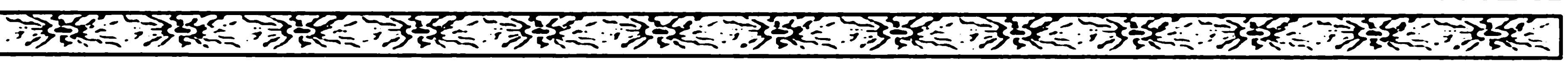

CoRRía la déCADA de 1870 y Buenos Aires no lograba quebrar la impresión general de una ciudad todavía típicamente colonial. El aspecto de rural y la atmósfera campesina, ese peculiar aire de extramuros que invadía al visitante cuando se alejaba del centro, las insuficiencias de una estructura urbana carente de agua potable, electricidad, pavimentos, medios de transportes... las conductas $\tan$ poco «civilizadas» de unos habitantes tan poco «trabajadores"... sustentaron la convicción en los sectores dirigentes -terratenientes, profesionales y comerciantes que administraban la ciudad y dirigían la nación- de que todo estaba aún por hacer. Para torcer el rumbo, estos hombres no dudaron a la hora de priorizar las medidas: el recambio y el aumento de la población. Terminar con el «desierto» era prioritario si se quería construir una nación moderna. Abrir el país -como lo declaraba el preámbulo de la Constitución nacional promulgada en 1853- a «todos los hombres del mundo que quieran habitar el suelo argentino" fue el marco institucional, apoyado y continuado por una campaña gubernamental que difunde y promociona las ventajas que, consideraba, ofrecía Argentina. La publicidad se acompañó con facilidades para el traslado a través de la financiación del pasaje y la gratuidad 
durante los primeros cinco días del alojamiento y la comida en el «Hotel de Inmigrantes» a los pasajeros de tercera clase.

Brazos necesarios para el desarrollo económico, los inmigrantes fueron vistos además como los principales motores para la modernización social, cultural y política. Los males del país -como lo señaló entre otros Domingo Faustino Sarmiento- residían en un estilo de vida moldeado en el marco natural brindado por el espacio americano y que España nos había generosamente legado. Si España era el problema, si la herencia ancestral de "amor a la ociosidad e incapacidad industrial» que compartían tanto espanoles como indígenas explicaban la desventura argentina, la solución la brindaría Europa. Así, la «inmigración permitiría construir una nación contra su pasado más bien que a partir de él»1.

La sociedad aluvional en que se convirtió paulatinamente Argentina transformó la figura del inmigrante en una evidencia imposible de soslayar en la vida cotidiana. En la década de 1880 eran un millón los extranjeros ingresados en un país de tres millones y medio de habitantes y en 1914 el $30 \%$ de la población estaba compuesto por extranjeros. Dentro de este marco, la ciudad de Buenos Aires desempeñó un papel central, al quintuplicar su población y albergar en su interior más de un $50 \%$ de población inmigrante ${ }^{2}$.

${ }^{1}$ Halperin Donghi, T., «¿Para qué la inmigración? Ideología y política inmigratoria en la Argentina (1810-1914), en El espejo de la historia. Problemas argentinos y perspectivas latinoamericanas, Sudamericana, Buenos Aires, 1987, p. 229.

2 En 1869, por ejemplo, según el Primer Censo Nacional, la ciudad de Buenos Aires tenía 180.000 habitantes para llegar a 650.000 en 1895 (Segundo Censo Nacional de Población).

Las dos corrientes inmigratorias más importantes fueron la italiana y la española. En el caso de la inmigración italiana, las regiones que aportaron más inmigrantes fueron las del norte, Nororiente y centro hasta 1895. A partir de esta fecha se revierte la tendencia y el mayor número proviene del área meridional $e$ insular. Esto equivale a un aporte numérico general mayor de estas regiones, en la medida en que se produce cuando la migración italiana fue más voluminosa (Cacopardo, C. - Moreno, J.L., "Características regionales, demográficas y ocupacionales de la inmigración italiana a la Argentina (1880-1930)», en Devoto, F. Rosoli, G. (Comps)., La inmigración italiana en la Argentina, Biblos, Buenos Aires, 1985, p. 63). 
Esta presencia incuestionable planteó de hecho el problema de la nacionalización de las masas, invitó a reflexionar sobre la multitud y la gobernabilidad de la nación y se conectó con la llamada "cuestión social», que, en el plano del movimiento obrero, estaba contemplada dentro de la propuesta socialista y anarquista. La agitada vida urbana y los problemas derivados de la urbanización acelerada (vivienda, servicios sanitarios, epidemias, etc.) dieron margen para poner en tela de juicio la estabilidad entre el «orden y el progreso", lema con el que el general Julio Argentino Roca había iniciado su primera presidencia en 1880.

El progreso material asentado en la expansión económica fue palpable y celebrado con entusiasmo por los intelectuales que se adherían a la modernización en curso, pero pronto fue acompanado por la denuncia y por la propuesta de tomar las medidas necesarias para reencauzar una "civilización» insuficiente o totalmente ausente. El término civilización fue utilizado en las últimas décadas del siglo pasado con mayor frecuencia que el de modernidad y, si bien gozó de distintas acepciones, la más corriente fue la que lo asociaba con un conjunto de comportamientos determinados por la razón y ejemplificadores del control de los impulsos, la represión de las pasiones y las conductas autocontroladas ${ }^{3}$. Portadora de conquistas como la racionalidad, el trabajo y la ciudadanía, la modernidad estaba implícita en los inmigrantes cuyas ven-

La inmigración española provenía del norte peninsular. Los más numerosos fueron los gallegos, siguiéndoles, a cierta distancia, los asturianos, catalanes, leoneses y vascos. Pero el aporte inmigratorio de cada una de estas regiones no fue homogéneo, observándose importantes variaciones en el tiempo y notables concentraciones provinciales y comarcales al interior de estas mismas regiones (Yañez Gallardo, C., Argentina como país de destino. La emigración española entre 1860-1930, mímeo).

${ }^{3}$ Norbert Elias definió el «proceso de civilización» como la «interiorización individual de las prohibiciones que, antes, eran impuestas desde el exterior... en una transformación de la economía psíquica que fortifica los mecanismos de autocontrol ejercido sobre las pulsiones y emociones y hace pasar del control social al autocontrol» (Elias, N., La société de Cour, Flammarion, Paris, 1985, p. 212. La traducción es nuestra).

${ }^{4}$ Para un estudio de la modernidad de la ciudad de Buenos Aires en las décadas de 1920 y 1930 analizada a partir de textos literarios: Sarlo, V., Una mo- 


\section{SANDRA GAYOL}

tajas culturales habían sido inicialmente subrayadas sin dudar ${ }^{4}$. Pero, cuando muchos extranjeros blancos expresaron comportamientos que sólo se achacaban al "bárbaro nativo", su papel irrecusable como destructores de las «degradantes habitudes españolas» -como se decía comúnmente en la época- fue relativizado e impulsó, si bien no el abandono de la «ideología proinmigratoria» ${ }^{5}$, sí una mirada hacia el extranjero con matices y reticencias. Con el "buen inmigrante» puede venir también el «mal inmigrante», y dentro del bloque de inmigrantes van apareciendo a su vez distintas valoraciones derivadas de su procedencia étnica ${ }^{6}$.

En la grilla de comportamientos asociados con la modernidad y de los cuales se derivaban valores morales el honor ocupó un lugar muy importante. Como valor que encauzaba la dignidad, autoestima y respeto personal, era deseable y esperable en una sociedad aluvional, donde algunos de sus miembros comienzan a ser denunciados por "trabajar como animales» ${ }^{7}$. Pero las consecuencias a veces nefastas derivadas de su defensa remitían directamente a la falta de control de las pulsiones indispensables en hombres modernos y alimentaban la convicción cada vez más arraigada de una Buenos Aires invadida por una criminalidad violenta. La defensa del honor consumada en el enfrentamiento físico fue rápidamente asimilada con el legendario "culto del coraje», integrante, según los intelectuales positivistas, de la serie de lastres que

dernidad periférica: Buenos Aires 1920 y 1930, Nueva Visión, Buenos Aires, 1988. Una crítica a la modernidad en América Latina de fines del siglo XIX, y también de este siglo, desde los excluidos, mujeres, negros y homosexuales a partir de sus territorios, representaciones y cuerpos: Ludmer, J. (Comp)., Las culturas de fin de siglo en América Latina, Beatriz Viterbo, Rosario, 1994.

${ }^{5}$ Halperin Donghi, T., Op. cit., p. 196.

${ }^{6}$ Para la estructuración y reestructuración de una escala jerárquica de grupos étnicos en el seno de la masa de trabajadores: Falcón, R., «Inmigración, cuestión étnica y movimiento obrero (1870-1914), en Devoto, F. - Miguez, E. (Comps.), Asociacionismo, trabajo e identidad étnica. Los italianos en América Latina en una perspectiva comparada, CEMLA-CSER-IEHS, Buenos Aires, 1992.

${ }^{7}$ Esta visión estuvo inicialmente asociada con los italianos. 
dificultaba la constitución de una ciudadanía cabal ${ }^{8}$. Al zanjarse los conflictos por honor de forma predominantemente privada, desconocían a la institución judicial, institución que, junto con otras, buscaba trazar el límite en cuyo interior se asimilarían los sectores integrables a la modernidad. Reencauzar los comportamientos que genera el honor, pero también bregar por dar prioridad a una determinada definición de él, era necesario tanto para fijar jerarquías como para construir un país moderno. Analizar el juego de cruces $y$ tensiones entre el honor y la modernidad es el objetivo general de las páginas que siguen.

El período analizado es el comprendido entre 1880 y 1910 y el área geográfica transitada es esencialmente la de la ciudad de Buenos Aires. La década de 1880 marca de alguna manera el punto de partida de las transformaciones demográficas, económicas, sociales, culturales y políticas que darán origen a la denominada "Argentina moderna». El final de nuestro período es también el final de una etapa. Como lo señalan distintos trabajos desde diferentes perspectivas de análisis, la Buenos Aires del centenario y la del primer presidente elegido por medio del sufragio universal masculino viene a cerrar el ciclo iniciado en 1880. Buenos Aires, ciudad-capital de la Argentina, comanda los cambios y también los experimenta, brindando por ello un escenario posible para comenzar a reflexionar sobre este tema complejo. De este modo, y aun admitiendo la existencia de subperíodos, creemos que 18801910 connota una etapa coherente de estudio.

${ }^{8}$ Cuando Agustín Alvarez (1857-1914), uno de los representantes del positivismo argentino, enumera los factores que dificultan la constitución de la ciudadanía, afirma que "el culto del coraje, la incapacidad autocrítica, el saber que persigue el engaño del otro... el valor para atropellar al prójimo y la habilidad ilustrada para deslumbrarlo y engañarlo son auténticas llaves del porvenir para un argentino por la consideración pública que reclutan» (Álvarez, A., "La leche de clemencia», en Manual de patología política, Buenos Aires, 1889). Una obra también muy conocida y asentada en el culto al coraje es la de García, A., La ciudad indiana, Buenos Aires, 1928. 
La llegada de los inmigrantes precede y su irrupción masiva coincide con la incorporación de la economía argentina al mercado mundial como uno de los principales países exportadores de materias primas (cereales y carnes), con el proceso de centralización y consolidación del Estado y con el despliegue de un tejido de instituciones y prácticas sociales tendientes a homogeneizar la estructura social. El cataclismo producido por la mera presencia de individuos cuyo arribo provocó la tasa de crecimiento de población más alta del planeta ${ }^{9}$, con relación a sus habitantes originarios, puso en evidencia que la "estática del orden y la dinámica del progreso» ${ }^{10}$ no siempre podían convivir armónicamente.

El desfase entre expectativas y resultados visibles motivó, en un fin de siglo fructífero en ideas diversas, convergentes y contradictorias, la aparición de teorías que, desde posturas muy variadas, buscaban.interpretar el presente y proponer medidas para superarlo. En este desfile ideológico, en cuyo seno convivían tendencias tan dispares como el vitalismo, el decadentismo o el espíritu modernista $^{11}$, el positivismo se constituyó en la ideología domi-

${ }^{9}$ La tasa anual de crecimiento fue del $4 \%$. El promedio de crecimiento anual de la ciudad de Buenos Aires entre 1869 y 1895 llegó al 44 por mil. Durante el siguiente período censal, de 1895 a 1914, el índice decreció ligeramente al 43 por mil (Scobie, J., Buenos Aires. Del centro a los barrios, 1870-1910, SolarHachette, Buenos Aires, 1977, p. 28. 1987, p. 13.

10 Terán, O., Positivismo y nación en la Argentina, Puntosur, Buenos Aires,

${ }^{11}$ Ibid., p. 11. Para una aproximación sobre las ideas a fines de siglo: Romero, J.L., Las ideas políticas en la Argentina, FCE, Buenos Aires, 1992; Halperin Donghi, T., «1880: Un nuevo clima de ideas», en Halperin Donghi, T., El espejo... Op.cit.

A diferencia del positivismo, que ha merecido estudios puntuales, son muy escasos los trabajos referidos a las otras corrientes ideológicas. Sobre el decadentismo derivado del "sensualismo positivista» denunciado por los intelectuales católicos: Auza, N., Católicos y liberales en la generación del ochenta, Ediciones Culturales Argentinas, Buenos Aires, 1975. Una aproximación despojada de la influencia y visión pregonada desde la Iglesia católica: Santamaría, D., "Estado, Iglesia e inmigración en la Argentina moderna», en CEMLA, n. 14, abril de 1990. 
nante $e^{12}$ hasta aproximadamente 1910 , cuando el nacionalismo se plantó como su principal rival ideológico y, de la mano de Manuel Gálvez y Ricardo Rojas, buscó recuperar el hispanismo, con frecuencia maltratado por los positivistas ${ }^{13}$.

La capacidad del positivismo para hablar «desde la institución ${ }^{14}$, es decir, su constitución en ideología dominante, se debió a la posibilidad de articular un discurso y un set de prácticas verosímil sobre los efectos no deseados de la modernización en curso y sobre los impedimentos para que dicho proceso pudiera desplegarse con eficacia ${ }^{15}$. Complejo y relativamente diversificado, el diagnóstico de los "males" presentes realizado por el movimiento positivista descansaría diversamente, según los autores, en la integración biológica, como en el caso de José María Ramos Mejía; en los avatares de la composición étnica, subrayado con énfasis por Carlos Octavio Bunge; en la construcción de una comunidad moral y jurídico-institucional, destacada por Juan Agustín García, o en la renovación de las costumbres políticas, como lo expresó Agustín Alvarez ${ }^{16}$. Más allá de estas diferencias, la recurrencia al darwinismo social y la invocación del pasado como instrumento explicativo del presente fueron rasgos esencialmente compartidos. Carlos Octavio

12 Sobre el positivismo argentino: Romero, J.L., El desarrollo de las ideas en la sociedad argentina del siglo XX, Solar, Buenos Aires, 1965; Soler, R., El positivismo argentino, Paidós, Buenos Aires, 1968; Todo es historia (número dedicado a "Los positivistas argentinos»), n. 173, octubre de 1981; Biagini, H.(Comp.), El movimiento positivista argentino, Belgrano, Buenos Aires, 1985; Terán, O., Op.cit.; del mismo autor: José Ingenieros: pensar la nación, Alianza, Madrid, 1986; Vezzetti, H., El nacimiento de la psicología en la Argentina, Puntosur, Buenos Aires, 1988; Ruibal, B., Ideología del control social. Buenos Aires 1880-1920, CEAL, Buenos Aires, 1993.

13 Sobre el nacionalismo puede consultarse: Ibarguren, F., Orígenes del nacionalismo argentino, Celcius, Buenos Aires, 1969; Zuleta Álvarez, E., El nacionalismo argentino (2 Vols.), La Bastilla, Buenos Aires, 1975; Barbero, M.I. - Devoto, F., Los nacionalistas, CEAL, Buenos Aires, 1983; Quijada, M., Manuel Gálvez: 60 años de pensamiento nacionalista, CEAL, Buenos Aires, 1984; Nascimbene, M., El nacionalismo liberal y tradicionalista, Biblos, Buenos Aires, 1996.

14 Terán, O., Positivismo... Op. cit.

${ }^{15}$ Ibid.

${ }^{16}$ Vezzetti, H., El nacimiento... Op. cit., p. 14 y 19. 
Bunge (1875-1918) es, quizás, el representante más nítido de esta estrategia de conocimiento y su figura puede ser instructiva para comenzar a recorrer la relación presente/pasado de la que brota nítidamente la dupla honor/modernidad. Bunge fue uno de los intelectuales más significativos del período. Reflexionó y elaboró teorías sobre la Argentina e Hispanoamérica contemporáneas y emitió opinión en su praxis judicial. En su tarea cotidiana de administrar justicia se encontró en numerosas ocasiones con el honor, con los inmigrantes y con los "otros», que no siempre resultan asimilables a los 'otros' que construye en sus elucubraciones teóricas.

Abogado, juez de la nación y especialista en derecho penal, nieto de inmigrantes alemanes e integrante de la minoría acaudalada gobernante del país ${ }^{17}$, explicó los males argentinos y latinoamericanos apoyándose en la sociología psicobiológica. En Nuestra América, el más difundido de sus trabajos, publicado en 1903, realizó una «autopsia del cuerpo nacional con el fin de coadyuvar modestamente a algún diagnóstico para que se atienda sus dolencias» ${ }^{18}$. Como corresponde a los "grandes clínicos de consulta», hace un «diagnóstico general para que luego los especialistas curen por partes al paciente, quién los riñones, quién el estómago, quién los bronquios» ${ }^{19}$, recurriendo a la, como él mismo la llama, "divinidad suprema», es decir, la ciencia, buscando así el reconocimiento científico de su obra y mostrando su adhesión al clima ideológico imperante que aspiraba a extender la cientificidad al campo de las ciencias sociales.

Comprender el mundo social que la modernización había traído consigo lo induce a un viaje por el pasado hispanoamerica-

17 Sobre la familia Bunge en general puede consultarse: Cárdenas, E.J. Paya, C.M., La familia de Octavio Bunge (tomo I), Sudamericana, Buenos Aires, 1995; de los mismos autores: La Argentina de los hermanos Bunge. Un retrato intimo de la elite porteña del 1900, Sudamericana, Buenos Aires, 1997.

18 Bunge, C.O., Nuestra América (ensayo de psicología social), Valerio Abeledo, Buenos Aires, 1905, p. 22.

${ }^{19}$ Ibid., p. 214. 
no y español, en el que destila sin cansancio y sin pudor un biologismo extremo derivado rápidamente en racismo ${ }^{20}$.

España sirve de arranque; la Madre Patria es el punto de partida, es el inicio de un viaje por países occidentales erigidos como "otro", "otro" geográfico, "otro" espejo que, siguiendo el recetario propuesto, es factible de imitar o de superar.

Inglaterra, Francia y Alemania son la antítesis de España, son el presente exitoso europeo. Presente y fuente, raíz cuya evolución viene a explicar ese presente. Estados Unidos de América es también el presente, pero es esencialmente el devenir. En la mirada hacia el país del norte emerge el "otro", un «ellos» ejemplificador de la modernidad que ha podido nacionalizarse exitosamente y que se coloca frente a un «nosotros» hispanoamericano en dificultad.

El éxito de estos tres países europeos y del hermano-enemigo norteamericano, que demostró en la guerra de 1898 contra España su capacidad y vocación expansionista ${ }^{21}$, es explicado por distintos factores (clima, ubicación geográfica, características del suelo, estado de la economía) que terminan supeditados o subsumidos a la raza devenida en el principal ideologema explicativo del desarrollo histórico.

«Hoy día, si Inglaterra, si Francia, si Alemania llegan a grande altura en la civilización moderna, es porque son producto, dos de ellas, de variedades de raza germánica; y la otra,

${ }^{20} \mathrm{Si}$, como dijo Real de Azúa, el «día que se haga la historia del racismo hispanoamericano se van a llenar muchas páginas", es cierto también que, en el caso argentino, Bunge es el ejemplo más primario y extremo que no aparece en sus compañeros de escuela, como José María Ramos Mejía, José Ingenieros o Agustín Álvarez.

21 Terán, O., Positivismo... Op. cit. Según el autor, esta guerra y la clara predominancia que el país del norte va adquiriendo en el contexto mundial, limitadora del "argentinocentrismo" defendido por Bunge y otros intelectuales de la época, son las causantes del paulatino abandono del agudo antihispanismo que había caracterizado la obra de Carlos Octavio Bunge. Sobre la ilusión del "vanguardismo" argentino construido a fin del siglo XIX con el "salto modernizador" de la ciencia: Salessi, J., "Identificaciones científicas y resistencias políticas», en Ludmer, J., Las culturas... Op. cit. 
mezcla de latinos y germanos, es decir, variantes del gran grupo etnográfico ario (asioeuropeos) (...) los colonos anglosajones tuvieron siempre mujeres europeas pura sangre. $\mathrm{Si}$ faltaban, enviábales prostitutas la metrópoli en buques mercantes $(. ..) \nu^{22}$.

La explicación del éxito permite presumir el porqué de los fracasos, pero desbroza además el terreno para su teoría de la mezcla de razas deseable.

"Desgraciadamente predominan en España las razas híbridas, razas estériles, porque los elementos de que están formadas, tendiendo a organizarse según diversos tipos de estructura, reasumiendo herencias antagónicas, llevando latentes atavismos, destruyen mutuamente las actividades fisiológicas que precontenían y no dan más que productos de decadencia, si dan alguno. Las diversas sangres de que están formados los españoles son incombinables. Así todo el mundo está en contradicción consigo mismo. iSi al menos hubiera predominado el elemento semítico! Habríamos tenido una civilización a la oriental, con todos sus inconvenientes pero con todas sus ventajas (...) (sic) $)^{23}$.

Esta herencia antagónica trasladada a Hispanoamérica profundizó su debilidad por la esencia de la conquista, asentada en la avaricia, y por la consiguiente mezcla entre españoles y razas «más débiles», como la negra y la indígena. Teoría de la degeneración y de la decadencia que no se opone a la mezcla de razas, sino que promueve una mezcla selecta.

«(..) para que un pueblo se civilice y progrese necesita que sus elementos no pertenezcan a géneros demasiado diferentes, lo mismo que las especies orgánicas para reproducirse (...), el inconveniente no está en la mezcla de razas afines, sino en la mezcla de razas incongruentes, inamalgables $(\ldots))^{24}$.

${ }^{22}$ Bunge, C.O., Nuestra... Op. cit.

${ }^{23}$ Ibid., p. 56.

${ }^{24}$ Ibid. 
De esta «mezcla incongruente» nace el «elemento extraño etnográfico", otredad en la que abreva la psicología del hispanoamericano asentada en la trilogía: pereza-tristeza-arrogancia.

Carlos Octavio Bunge retoma aquí la ya habitual denuncia sobre la escasa vocación por el trabajo entre la población nativa. La pereza, llamada también haraganería, se da la mano con la arrogancia para desatar toda una lista de calamidades. Heredada de la Madre Patria y apropiada por nuevos actores este:

"culto del valor personal, al trocarse en criollo, perdidos ya los frenos medioevales (moral caballeresca) y religiosos (cristianismo) que antes la morigerasen y contuvieran, se hace una idea fuerza social de incontrastable violencia (...). llega a generar egolatría o autolatría desesperada, anárquica... ( y es) más fuerte en los mestizos, especialmente en los mulatos (incluyéndose en esta designación a los que llevan en sus venas pequeñas fracciones de sangre africana). En ellos puede la arrogancia tomar el colorido de una suprema envidia, más rastrera y voraz que la serpiente. Sobre todo en ciertos mulatos y amulatados y por ciertas razones (...) (sic) $)^{25}$.

Exceso, transgresión permanente, ausencia de ductilidad, sinónimo de violencia. La arrogancia es una muestra de «pura fanfarronería y matonismo" que, si bien permite explicar el fenómeno político del caudillismo, también es útil a Bunge para incorporar al "extraño moral». Esto es, el "otro" que se apropia de comportamientos y valores prostituyéndolos de su sentido originario. Ese "otro", considerado como pura ajenidad, toma no sólo lo que no le corresponde, sino que lo hace en un sentido formal y meramente superficial. Esta tesis, que denuncia el desconocimiento de la ley, la autoridad y la voluntad del Estado, trasladada al terreno político práctico, lo conduce a aconsejar en sus Estudios filosóficos una lógica de enfrentamiento absoluto con la otredad expresada 
SANDRA GAYOL

en la máxima que recomienda tratar de «vencer al extraño por todos los medios de que dispongas».

En esta galería de «otros» geográficos, etnográficos y morales entrecruzados es fácil imaginar el guiño positivo y cómplice que concede a la inmigración: “(...) más económico, más constante, más trabajador (...), que va, como los clásicos labriegos de Chipre a la vendimia, cantando a sus faenas» ${ }^{26}$, el recién llegado permitirá superar estas alteridades y dificultades al borrar el fondo racial hispánico e indígena.

La capacidad de Buenos Aires para asimilar la cultura europea provoca que, "al llegar a sus playas el inmigrante se siente, no en su casa, mejor que en su casa ${ }^{27}$. Sinónimo de civilización como los «ferrocarriles, los alambrados, la policía y la justicia disciplinada» ${ }^{28}$, una "vez nacionalizados y acriollados, amoldándose a los sentimientos e ideas del litoral, los mejora y tiende a formar una psicología argentina, la más bella y poderosa, la que amalgamará y refundirá en un crisol todos los factores y regiones para que (se) fundan en purísimo oro ${ }^{29}$. Finalidad ésta garantizada en principio por la capacidad de atracción que ejerce lo que considera la generosa política argentina, sus leyes liberales, la abundancia de su producción y hasta la belleza de su cielo.

El curso de los acontecimientos disparó una inflexión a este optimismo exacerbado. Las crisis económicas y la creciente conflictividad social marcaron la actuación de Carlos Octavio Bunge en dos direcciones. Como hombre de derecho y responsable de la administración de justicia castigó los excesos de los comportamientos, los actos de violencia y la violación de la ley; como pensador participó de la división global que se iba trazando entre el «buen y el mal inmigrante». En este recorrido redefinirán «viejas» y nacerán «nuevas» alteridades.

27 Ibid., p. 212.

${ }^{28}$ Ibid., p. 193.

${ }^{24} \mathrm{Ibid}$, p. 230. 


\section{LA VIOLENCIA DE TODOS}

Las crecientes huelgas que con diferente intensidad, duración, causas, resultados y objetivos empezaron a manifestarse en las últimas décadas del siglo, los conflictos entre el capital y el trabajo ${ }^{30}$, el proceso de constitución de la clase obrera urbana, los intentos de difundir ideas que planteaban modificaciones sustantivas de la sociedad ${ }^{31}$ y las crecientes presiones por ampliar el escenario político edificaban, y al mismo tiempo alimentaban, la convicción de un medio urbano escurridizo y rebelde que amenazaba con superar la capacidad de control policial y judicial.

Desde las cátedras universitarias, las revistas especializadas y la prensa se postulaba la convicción de una generalización del crimen en la ciudad ${ }^{32}$. Buenos Aires, definida en términos de «cloaca urbana» ${ }^{33}$, estaba acechada por la amenaza de la peste, la violencia, la inmigración y el cosmopolitismo. Hidra a la que se opondrá el mundo rural y campesino como escenario propicio para fomentar y moldear la identidad argentina, azotada por una criminalidad violenta que, al ser asociada por muchos autores con la población italiana y española, "los dos países europeos con mayores índices de criminalidad de sangre ${ }^{34}$, volvía la mirada hacia esa capa de

${ }^{30}$ Sobre la política del Estado frente a los trabajadores: Suriano, J., «El Estado argentino frente a los trabajadores urbanos: política social y represión, 18801916", en Anuario 14, Escuela de Historia, Facultad de Humanidades y Artes. Segunda Epoca, UNR, 1989-90.

${ }^{31}$ Falcón, R., El mundo del trabajo urbano (1890-1914), CEAL, Buenos Aires, 1986; Zaragoza, G., Anarquismo argentino (1876-1902), De la Torre, Madrid, 1996.

${ }^{32}$ La Revista de Criminología, Psiquiatría y Medicina legal contenía en casi todos sus números un artículo alusivo a la violencia. El tono predominante en estos escritos puede ser ilustrado recurriendo al artículo publicado en 1914: «...en pocos años su población (la de Buenos Aires) ha aumentado de un modo considerable, ha atraído a su seno elementos de cultura y progreso de toda especie, y se han desarrollado a tal punto sus energías, sobre todo en el orden económico y comercial, que toda ponderación sería pequeña ante esta realidad; sin embargo también ha visto crecer y crecer la actividad delictuosa y no en relación al mayor número de habitantes, sino en una proporción evidente y abrumadora».

${ }^{33}$ Ruibal, B., Op. cit.

${ }^{34}$ Esta aseveración corresponde al criminólogo positivista Pedro Moyano Gacitúa (citado por Ruibal, B., Op. cit., p. 18). 


\section{SANDRA GAYOL}

inmigrantes indeseados y los colocaba, nuevamente, a la par de los nativos.

Sin embargo, como lo ha demostrado Beatriz Ruibal ${ }^{35}$, si en el curso de nuestro período de estudio los delitos contra las personas aumentan, también lo hacen y en mayor proporción los delitos contra la propiedad, poniéndose en evidencia de este modo los cambios que se estaban produciendo en la dinámica de la ciudad. Por otro lado, entre los delitos contra las personas predominan los de menor violencia, es decir, aquellos derivados de lesiones $y$ homicidios por imprudencia, sobre los homicidios $y$ crímenes violentos en general ${ }^{36}$. Como lo reconocía la misma policía en un informe de 1904: si existía «el vicio tradicional de llevar armas, esto no obedecía al propósito deliberado de matar». Si Buenos Aires fue mucho menos violenta que lo denunciado y si su violencia fue selectiva, en la medida en que fue ejercida por habitantes que distinguían con claridad entre la pelea con violencia como profesión y el valerse de ella sólo para defender causas nobles $^{37}$, fue identificada por las élites y desde el Estado como una barbarie extemporánea en relación con el progreso material alcanzado y frente a la cual la sociedad tenía derecho a defenderse generalizando sus controles.

Desde el Estado se diagramó la creación, reestructuración y cruce de instituciones encargadas de trazar el límite en cuyo interior se asimilarían los sectores integrables a la modernidad y prácticas coercitivas que, también institucionalmente, expulsarían a todos aquellos renuentes a integrarse a la estructura nacional.

${ }^{35} \mathrm{Ibid}$. Véase especialmente pp. 17-31.

${ }^{36}$ Ruibal, B., Op. cit. Sobre el mismo tema y siempre desde una perspectiva de análisis macro puede consultarse también: Johnsons, L. - Blackwelder, J., "Estadística criminal y acción policial en Buenos Aires, 1887-1914», en Desarrollo Económico, Revista de Ciencias Sociales, vol. 34, n. 93, abril-junio de 1984. De los mismos autores: "Changing Criminal Patterns in Buenos Aires 1880 to 1914", en Latin American Studies, vol. 14, n. 2, 1985.

${ }^{37}$ Nos permitimos remitir a: Gayol, S., Sociabilité a Buenos Aires: les rencontres dans les débits de boissons, 1860-1900 (tesis de doctorado), Ecole des Hautes Etudes en Sciences Sociales (EHESS), París, junio de 1996. 
Así, la policía de la capital se reorganizó ${ }^{38}$, se dictó el Código Penal en 1891, el Código de Procedimientos en lo criminal en 1889 y la Ley de Residencia en 1902. Esta ley, que Miguel Cané había presentado en público en 1899, bajo el nombre Expulsión de extranjeros, fue sancionada rápidamente en 1902, cuando se desarrolló la primera huelga general, e insistía en el problema que crea el ingreso de las ideas y las actividades anarquistas, al tiempo que colocaba el tema de la inmigración con respecto a las garantías jurídicas que la constitución de 1853 aseguraba a los extranjeros. Ahora el Poder Ejecutivo podía, por decreto y sin intervención judicial, expulsar a cualquier extranjero «que haya sido condenado o sea perseguido por tribunales nacionales o extranjeros $(y)$ cuya conducta pueda comprometer la seguridad nacional, turbar el orden público o la tranquilidad social». Al mismo tiempo, se lo facultaba para impedir la entrada al país de "todo extranjero cuyos antecedentes autoricen a incluirlo entre aquellos a que se refieren los artículos precedentes».

A la par de estas medidas represivas y coercitivas, se buscó ejercer un control sobre la inmigración. La toma de distancia, desidealización y replanteo del el aporte inmigratorio no debe pensarse como un intento de frenarlo ${ }^{39}$. Sí debe leerse como el cambio de una mirada y como el inicio de una práctica selectiva. La inmi-

${ }^{38}$ Para un estudio sobre la conformación del plantel policial, la percepción de la actividad y la vinculación con la ley de los agentes policiales nos permitimos remitir a: Gayol. S., "Entre los deseable y lo posible: perfil de la policía de Buenos Aires en la segunda mitad del siglo XIX», en Estudios Sociales, n. 10, primer semestre, 1996.

${ }^{39}$ Además de los trabajos de Bunge, también José María Ramos Mejía y José Ingenieros expresan el enfoque positivista sobre el inmigrante: Ramos Mejía, J.M., Las multitudes argentinas. Estudio de psicología evolutiva para servir de Introducción al libro "Rosas y su Tiempo», La Cultura Argentina, Madrid, 1912 (la primera edición es de 1899). Ingenieros, J., Sociología argentina, obras completas, Elmer, Buenos Aires, 1957 (particularmente el volumen 8).

Mucho se ha escrito sobre los ajustes necesarios que efectuar frente al aluvión inmigratorio y sobre las diferentes visiones y propuestas que el mismo depara. Siguen siendo clásicos: Halperin Donghi, T., «¿Para qué... Op. cit.; Onega, G., La inmigración en la literatura argentina (1880-1910), Capítulo, Buenos Aires, 1982; Vezzetti, H., La locura... Op. cit. 
gración continuaba siendo todavía posible y necesaria, pero debía ser fomentada y encauzada por el Estado. Éste debía, además, ser capaz de gobernar los procesos sociales y, como sostenían sólo algunos, también los económicos.

Para José Ingenieros «se impone evitar que otros grupos sociales nos endosen su población criminal; es indiscutible que cada Estado debe preocuparse de sanear su ambiente mediante una defensa social bien organizada, y no descargando sobre otros países sus bajos fondos degenerativos antisociales ${ }^{40}$.

Carlos Octavio Bunge comparte esta perspectiva. Desde la misma óptica afirma que:

«El Atlántico arroja sobre estas playas, con el limo fecundo de la inmigración, también muchos estériles restos de Europa. Este mal elemento inmigratorio, aunque en ínfima minoría sin duda, parodia las características del criollo, generalmente deformándolas. Los extranjeros que hacen aquí de Moreiras imitan la clásica compadrada, en lo que ella tiene de más antisocial y pernicioso. El gracejo andaluz de los tiempos coloniales se prostituye a veces en groseros denuestos, y el castellano pundonor, en cobardes cuchilladas»" ${ }^{41}$.

Más morigerada y muy matizada es la descripción que en Las multitudes argentinas ${ }^{42}$ realiza José María Ramos Mejía del extranjero recién llegado al puerto de Buenos Aires. Asimilándolo con las primeras formas de la vida animal, el campesino, «vigoroso protoplasma de la raza nueva», cuando llega tiene y es:

"un cerebro lento, como el del buey a cuyo lado ha vivido; miope en la agudeza psíquica, de torpe y obtuso oído en todo lo que se refiere a la espontánea y fácil adquisición de

${ }^{40}$ Citado por Ruibal, B., Op. cit., p. 16.

${ }^{41}$ Bunge, C.O., Casos de derecho penal. Dictámenes del doctor C.O. Bunge, Arnoldo Moen Hno., Buenos Aires, 1911, p. 210.

${ }^{42}$ Ramos Mejía, J.M., Las multitudes.. Op. cit. 
imágenes por la vía del sentido cerebral. iQué obscuridad de percepción, qué torpeza para transmitir la más elemental sensación a través de esa piel que recuerda la del paquidermo en sus dificultades de conductor fisiológico! Crepuscular, pues, y larval, en cierto sentido, es el estado de adelanto psíquico de ese campesino, el vigoroso protoplasma de la raza nueva, cuando apenas pisa nuestra tierra. Forzosamente tiene uno que convencerse de que el palurdo no siente como nosotros» ${ }^{43}$.

El relato, sustentado en la percepción de elementos psicofísicos «naturales», incorpora el «nosotros» para designarse a sí mismo y a sus iguales sociales y lo coloca frente a un «ellos», frente a los "palurdos» extranjeros, que no designan dos momentos de adaptación al medio, sino el término mediante el cual se pone distancia entre los argentinos de varias generaciones y el recién llegado. Este "ellos», el "otro», absorbe también al nativo y diseña un "extraño moral», cuya base ya no es racial, únicamente racial, sino social y en muchos casos también linguística. En Ramos Mejía, en las sentencias dictadas por Carlos Octavio Bunge, revoloteando al final de Nuestra América, y en una porción de las élites dirigentes se terminan encontrando el «extraño moral» que en los ejercicios de interpretación histórica eran explicados por Bunge como el resultado de la mezcla de razas «incongruentes» con el "extraño moral» producto de la pertenencia a una clase social. El «estado larval del inmigrante» se funde con la «impericia y holgazanería del nativo» para dar cuerpo y edificar al "otro" social que deviene en amenaza al orden social, a la pureza de sangre, al monopolio del poder político y a la moral establecida. El honor cobra aquí todo su sentido. $\mathrm{Si}$, por un lado, nutre el discurso sobre la violencia, por otro lado alimenta la presencia del «otro/os» que copia, exagera y deforma un bien y un valor que deberá ser conservado, pero también profundamente modificado.

${ }^{43}$ Ibid., p. 84. El subrayado aparece en el original. 


\section{SANDRA GAYOL}

\section{HONOR MODERNO}

Los documentos generados por las instituciones del Estado permiten descubrir la importancia del honor en las interacciones sociales. Las afirmaciones generalizadas sobre la violencia lo ocultan, pero, por otro lado, lo ofrecen al análisis por la derivación en que puede incurrir su defensa. En un contexto general de denuncia sobre las limitaciones de la modernidad y sobre la violencia propia de sociedades poco civilizadas aparece la tensión entre el honor necesario de poseer e indispensable de encauzar.

Honor no es una palabra que empleamos para hacer alusión a ciertos comportamientos y valores, sino un valor al que se referían los actores sociales cada vez que debían explicar sus propios comportamientos o las conductas de los otros. Es una palabra que aparece, ciertamente, cuando los individuos declaran a la policía o a la justicia para explicar "cómo eso ha podido suceder», pero también encontramos su presencia en los diálogos entre los actores, en los comentarios y aun en las obras de ficción contemporánea. El honor describe lo que debe ser y también lo que es creîble.

Siguiendo los documentos policiales y judiciales ${ }^{44}$ a partir de la participación en los conflictos (en uno de cada cinco es invocado por los propios protagonistas para explicar sus actos o los de un tercero), las personas que involucra (un cuarto del total de personas que pasan por los archivos), las profesiones que toca (más de la mitad de un total de 107 profesiones) y las filiaciones que

${ }^{44}$ Hemos consultado completos los libros de notas de la policía de la ciudad de Buenos Aires correspondientes a la sección I (la que rodea a la plaza principal de la ciudad, hoy plaza de Mayo) y la XX (La Boca) y realizamos una selección al azar de algunos libros de notas de la XXIV (límite noroeste entre la ciudad y el campo). La información se inicia en 1863 y finaliza en 1903. En relación con los documentos judiciales hemos consultado los testimonios de sentencia de la justicia que se refieren a cualquier sección de la ciudad y que comprenden todo nuestro período de estudio. Para un informe detallado de estos documentos, sus limitaciones y la metodología utilizada nos permitimos remitir a: Gayol, S., "Sociabilité...», Op. cit., particularmente "Les sources et la méthologie». 
compromete (15 de las 26 nacionalidades diferentes registradas en las fuentes, entre casados y solteros, si bien predomina entre los solteros que no superan los 30 años $)^{45}$, el honor nos revela su significación para los actores sociales y emerge moldeando las relaciones de sociabilidad. Podría decirse, apropiándonos de la expresión de Julián Pitt-Rivers, que fue "una premisa común" en el Buenos Aires de la segunda mitad del siglo XIX ${ }^{46}$, un recurso a disposición de todos por medio del cual se pronunciaban sentencias diferentes.

Cuando se ingresaba a "esta esfera ideal» nacían rápidamente gestos que anunciaban su defensa. Es aquí cuando aparecen las armas, es aquí cuando aparecen muchas denuncias de actos de violencia.

En uno de cada dos incidentes en que el honor es invocado como causante de los comportamientos se usaron armas. Este hecho es significativo cuando vemos que, en los restantes casos en que el honor no aparece como causa, el arma es usada en uno de cada tres. Los motivos diferentes a la dignidad tendían a dirimirse a «mano desnuda» -trompadas, golpes de puño y empujones-. Las cuestiones de honor sólo terminaban en golpes de mano en uno de cada diez casos. Si el combate y el uso de armas (en primer lugar el cuchillo y luego el revolver) implicaban gestos que pretendían ser mortales, habían sido precedidos por un tiempo de espera, de incubación. El cuchillo o el revólver no se sacaba en primera instancia. Los individuos "estaban enemistados», "habían discutido», "no estaban en buena armonía». La violencia física con armas y de consecuencias posiblemente mortales fue precedida por gestos y palabras, también por encuentros previos o "desencuentros" resultantes de elecciones deliberadas. Las armas para defender el honor en la pelea se usaban después de todas estas estrategias. Los documentos insisten: «tenían antecedentes».

${ }^{45} \mathrm{Ibid}$.

46 Pitt-Rivers, J., Antropología del honor o política de los sexos, CríticaGrijalbo, Barcelona, 1979, p. 8. 
Más allá del carácter selectivo de esta violencia, independientemente de los matices y la discriminación motivada por la causa, como lo muestran los documentos a partir de un análisis detallado y micro, al aparecer asimilada la defensa del honor con «la falta de control de las pulsiones», también deberá ser encauzada.

«(...) el procesado vio destruida la salud, la honra, la vida de aquella tan amada criaturita indefensa, carne de su carne, sangre de su sangre. Sintió desquiciarse su casa y amargarse su vida, temiendo que una sombra de dolor y de vergüenza se interpusiera entre su cariño y la inocente víctima. Recordó que había tenido confianza y hasta amistad con el victimario, abriéndole las puertas de su hogar. El criminal se le antojaba más perverso aún desde que le había engañado para envilecer su casta... (sic). Todo hombre honesto, todo buen padre de familia, hallándose en la espantosa situación del procesado, sentirá ese sacudimiento de indignación y cólera. Si tiene dominio sobre sí mismo, y es persona ilustrada y culta, podrá acaso comprimirse y dominarlo. Entonces comprenderá que no puede caer un eterno baldón sobre aquella cabecita de cuatro años; que la enfermedad contagiada no es incurable; que el criminal no es más que un degenerado indigno de que le trate como a uno de sus pares; que ya la justicia, denunciado el delito, le impondrá la merecida pena... (sic). Pero todas estas ideas como inhibitorias y paliativas no han de contener a un hombre vulgar e inculto. Por el contrario, él procederá fatalmente. Su concepto de honor es más formal, sus nociones del crimen menos psiquiátricas, sus impulsos menos sofrenables. Los resortes de su organismo, sin el dominio de la reflexión y la disciplina, se falsearán momentáneamente en un crac doloroso y total. Una nube de sangre vendará sus ojos. Y, si en tal ocasión encuentra al autor del atentado, dejará de ser hombre antes que dejar de herir, y quizá de matar (...) debe ser hombre de genio violento. Confiesa usar siempre cuchillo, y ya ha sido acusado por lesiones. Estas últimas circuns- 
tancias, que serían en general desfavorables, pueden considerarse aquí favorables, moral y hasta jurídicamente. No se puede pedir a un hombre ignorante e impulsivo, que lleva habitualmente cuchillo en el cinto, un poder de contenerse y razonar sólo posible en un sujeto de elite, en un cerebral $(\ldots))^{47}$.

El honor fue para Bunge una causa ética que concede, por ende, a los actos un valor ético, pero que permite alertar al mismo tiempo sobre las derivaciones que puede traer una «concepción formal del honor".

$\mathrm{El}$ «otro moral» no se desprende aquí del «otro etnográfico», sino que su existencia se explica y en cierto sentido es previsible por la pertenencia social y no ya racial del autor. Si la razón, la reflexión que engendra «ideas inhibitorias y paliativas» está ausente en un individuo que "pertenece a la clase obrera y es analfabeto", es plausible de imaginar, no obstante, por medio de la educación. Las deficiencias culturales y la extracción social explican el "sentido formal» del honor, pero también alimentan el optimismo esperanzador de los efectos regenerativos de la redención por el trabajo. El ideal positivista de la recuperación y los efectos benéficos derivados del trabajo constante y sistemático cobra aquí todo su sentido y puede ser posible y esperable en este "buen marido, buen padre de familia, hasta buen hijo ${ }^{48}$, imposible de imaginar, en cambio, en todos aquellos que confunden la «nobilísima altivez (con) la innoble insolencia» ${ }^{49}$.

«(...) para el vulgo cosmopolita de esta ciudad, el gracejo andaluz y el pundonor castellano propenden a convertirse en algo que sólo puede llamarse -si el Sr. Juez me disculpa este neologismo necesario- guaranguería» ${ }^{50}$.

${ }^{47}$ Bunge, C.O., Casos..., Op. cit., pp. 133-135. El subrayado es del autor.

${ }^{48}$ Ibid., p. 136.

4) Ibid., p. 210-211.

s) Ibid. El subrayado es del autor. 
SANDRA GAYOL

Bunge, como la mayoría de los actores de la ciudad ${ }^{51}$, no confunde y distingue entre

«(...) el amor propio y la satisfacción de sí mismo con la arrogancia. Son dos cosas bien diferentes: el hombre que goza de sus méritos es un avaro que tiene un tesoro oculto, para que no se lo roben, en el último fondo de sus arcas, el corazón; pero el hombre que hace alardes de riquezas, el arrogante, es generalmente un pobre diablo que, sin poseerlas, quiere igualar y hasta superar en apariencia a quienes las poseen» ${ }^{52}$.

Una vez más la arrogancia, apoyada ahora en un gran corruptor: el dinero. El afán desmedido de lucro fue el exceso más planteado como otra falla de los extranjeros. La avaricia dio pie a nuevas alteridades que abarcaron desde el usurero, el estafador y el burgués aureus hasta el gringo pobre y casi animal. Las guaranguerías que rechaza Bunge no pertenecen a gringos amarretes, sino a burgueses, «niños bien vestidos» que al apelar a ellas no hacen más que mostrar las fallas de su cuna y de su apellido ${ }^{53}$. Estos advene-

${ }^{51}$ Entre los actores sociales aparece el rechazo a la compadrada, al compadre, por vincularse con la disrupción y el rompimiento del equilibrio social. Se asocia con gestos y poses desmedidos, con la agresión gratuita y sin causa que la justifique (Gayol, S., "Sociabilité...", Op. cit. Cap. VII: Op. cit.

52 Bunge, C.O., Casos... Op. cit., p. 327.

${ }^{53}$ Las descripciones sobre la vestimenta que se realizan entre los integrantes de las élites son muy significativas en este sentido. Junto a la frivolidad en el decorado de las casas y en la indumentaria, atribuida al mal gusto de quienes no siempre manejan e imponen los detalles distintivos, suele deslizarse el mal gusto del italiano guarango. Los comentarios que inspiró José Ingenieros, quien, paradójicamente, teorizó sobre la simulación desde el punto de vista clínico en La simulación en la lucha por la vida, son bien conocidos: "debo apresurarme a explicar que aquellas prendas, la galera y la levita, no eran como las que todos conocemos. Ingenieros iba embolsado en una espantable y descomunal levita gris, y del mismo color era el sombrero de copa alta y los anchos pantalones, tan anchos que parecían abombachados (...), el portador de semejantes horrores se creía elegantísimo, y los ostentaba por todas partes con desparpajo sonriente» (Gálvez, M., Amigos y maestros de mi juventud, Buenos Aires, 1927). Para la importancia de la ropa, los mecanismos distintivos que generaba y la pose nos permitimos remitir a: Gayol, S., El honor a través de sus manifestaciones gráficas: vestirse en Buenos Aires, 1860-1914, mímeo. 


\section{LAS ALTERIDADES DE LA MODERNIDAD}

dizos, que la novela de la época describió por primera vez y cuya actitud en las tesis psiquiátricas ${ }^{54}$ se conoce como simulación, no pueden beneficiarse de la "excusa ética» ni de la regeneración por el trabajo, pues sus actos, al falsear la realidad, son moralmente objetables $^{55}$.

"Contra estos hábitos decadentes, no puede menos que reaccionar una sociedad como la nuestra (...). Impónese la intervención oportuna de la policía y la ejemplarizadora severidad de la justicia (...). iHay que escarmentar a los guarangos! (...). Una serie de condenas, impuestas con la mayor severidad y publicadas fielmente por la prensa, han de bastar a tan útil escarmiento (...). La jurisprudencia ha de enseñarle que la libertad del uno concluye donde principia la del otro (...) $)^{56}$.

No hay simpatía sino temor frente a estos «arribistas» que irrumpen en escena. Un nuevo punto de encuentro entre Bunge, Ramos Mejía y las élites «tradicionales» de la ciudad. "En el proclamado rechazo del lucro y la ambición desmedida, el ego oligárquico denuncia defensivamente esa invasión extranjera que parece querer apoderarse de todo: riquezas, mujeres, prestigio, poder ${ }^{57}$.

"Otro" que no es pensado ni como "ajenidad" absoluta ni como «otro» social distante, pero posible de recuperar por el traba-

${ }^{54}$ Sobre este punto: Vezzetti, H., La locura... Op. cit.

${ }^{55}$ Esta definición de la "guaranguería" como simulación o como pose es condujo también en el discurso y en la práctica a considerar que el maricón es en realidad un hombre que, al simular lo femenino, posa de lo que no es. Así, el homosexual, como sujeto que trasciende las categorías del binarismo genérico, queda efectivamente eliminado (Molloy, S., "La política de la pose», en Ludmer, J. (Comp)., Op. cit., p. 135-136). Para el no reconocimiento de la diferencia en el imaginario sexual (heterosexual) de los textos de la literatura del 80: Moreno, M., "Dora Bovary (El imaginario sexual en la generación del 80), en Ibid. Sobre la homosexualidad puede consultarse también: Salesse, J., Médicos maleantes y maricas. Higiene, criminología y homosexualidad en la construcción de la nación argentina (Buenos Aires: 1871-1914), Beatriz Viterbo, Rosario, 1995.

56 Bunge, C.O., Casos... Op. cit., p. 212.

${ }^{57}$ Vezzetti, H., La locura... Op. cit. p. 198. 
jo, sino como «otro» que está próximo, que por estar próximo puede devenir en uno mismo, que se esfuerza por ser considerado como uno mismo, como un par. La caracterización del guarango y del canalla realizada por Ramos Mejía expresa con claridad el temor y la necesidad de frenar a quien:

"Ha recibido las bendiciones de la instrucción en la forma habitual de inyecciones universitarias; pero es un mendicante de la cultura (...). Por eso, aun cuando lo veáis médico, abogado, ingeniero o periodista, le sentiréis a la legua ese olorcillo picante al establo y al asilo del guarango cuadrado, de los pies a la cabeza. Le veréis insinuarse en la mejor sociedad, ser socio de los mejores centros, miembros de asociaciones selectas y resistir como un héroe el cepillo; le veréis hacer esfuerzos para reformarse y se reformará, a veces; pero cuando menos lo esperéis, saltará inesperadamente la recalcitrante estructura que necesita un par de generaciones para dejar la larva que va adherida a la primera" 58 .

Este "otro" también comete excesos. Muestra una indignación que es justa y necesaria, pero frente a la cual es incapaz de tener dominio. No saber imponerse es trocar en mujer, es ser «irritable, como una mujer voluble, impulsiva, vengativa ${ }^{59}$.

${ }^{58}$ Ramos Mejía, J.M., Las multitudes... Op. cit., p. 370.

${ }^{59}$ Bunge, C.O., Casos... Op. cit., p. 211. José María Ramos Mejía, en su registro social y biológico del comportamiento de las masas en la Argentina, compara a la multitud en su irracionalidad e inconsciencia con la bestia y con las mujeres. Con todo, en ambos autores están presentes las mutaciones que afectan a las significaciones de las mujeres, derivadas del papel central que adquieren en tanto garantes de la herencia y la preservación racial. La utilidad positivista reemplaza al encanto romántico (Vezzetti, H., La locura... Op. cit., p. 207). Por su parte, Francine Masiello observa que, en la perspectiva femenina, el lapso entre 1880 y la primera década del siglo siguiente representa un período de gran liberalización, ya que las mujeres se convirtieron en beneficiarias de las luchas por el poder y provocaron un debate alrededor de la "cuestión de la mujer» (Masiello, F., Entre civilización y barbarie. Mujeres, nación y cultura literaria en la Argentina moderna, Beatriz Viterbo, Rosario, 1997, pp. 114-143). De la misma autora: «Estado, género y sexualidad en la cultura del fin de siglo", en Ludmer, J., (Comp.), Op. cit. 
Es también una voz de mujer la elegida por Miguel Cané ${ }^{60}$ para hablar del honor, menos para cuestionar los comportamientos en que puede desembocar su defensa que para proponer una redefinición de la noción de honor.

En Ensayos ${ }^{61}$, recopilación de artículos que habían sido publicados individualmente con anterioridad, Miguel Cané parte de una "puerilidad" para armar un relato titulado "Una sombra en el espíritu», en el que los personajes encarnan "la razón social» y el «impulso individual». Alberto, al ver a Laura, quien ha sido su querida "por un puñado de oro (...) y durante dos dias", del brazo de Poloski, «siente un ímpetu desgarrador» que lo incita a provocar a su rival, primero con un roce, el insulto luego, las manos y el envío de su amigo Juan para que concertara el lance. Juan, en un principio, lo reprende diciendo: «Has hecho mal, Alberto, te has conducido como un niño, más aun, como un hombre sin sentido", $y$ ruega porque "metodice el espíritu y dé una dirección matemática a sus pasiones». Es una voz de mujer, es la propia Laura la que remarca su equívoco. Enterada de la concertación del duelo, escribe una carta a Alberto en la que se alza en contra del caos y se erige en defensora de la virtud republicana:

"(...) sé que van a batirse y a causa mía. Tú has sido siempre fino, atento y generoso conmigo y sin engaño alguno te he revelado mi franca simpatía. Yo no soy tu querida y bien conoces cual es mi vida: creo, pues, que tengo el derecho de vivir tranquila dentro de los límites de la ley (...) civil, como dice Arabella, que en sus primeros años fue mujer de un escribano. He sido amable contigo, lo mismo que con Poloski, porque la amabilidad es mi estado, es mi deber. ¿Es la manera de pagarme hacerse pedazos a brutales golpes de sa-

60 Miguel Cané (1815-1905), autor de la ya citada Ley de Residencia puesta en vigencia en 1902, además de escritor tuvo una intensa participación en la vida política. Fue diputado nacional y provincial, director de Correos y Telégrafos, embajador en varios países europeos y latinoamericanos, decano de la Facultad de Filosofía y Letras de la Universidad de Buenos Aires y ministro interino del Interior. ${ }^{61}$ Cane, M., Ensayos, La Tribuna, Buenos Aires, 1877. 
ble y dejarme, en caso de desgracia, no diré un remordimiento, porque no hay razón para él, sino un verdadero pesar? Es necesario que sean ustedes imbéciles para tener esos sentimientos que por mi parte no comprendo y que creía estaban ya únicamente destinados a hacer llorar a las viejas porteras sobre las columnas de una novela de folletín (...). Sean razonables y no me den el disgusto de matarse» ${ }^{62}$.

La razón adopta voz de mujer ${ }^{63}$. Este Miguel Cané, que argumenta con rostro y vestidos femeninos, es el que encontramos en otro relato incorporado en la compilación que se llama precisamente Honor moderno.

Frente a la "puerilidad" que dio origen al, en palabras del autor, «boceto" precedente, cuyo desarrollo se sitúa en el admirado pero también lejano París, Cané toma distancia ahora entre el "sentimiento vano que llaman honor»" que puede desembocar en actos brutales, muchas veces provocados por mujeres que han perdido la virtud, $y$ «el orgullo grande y noble cuando es iluminado por la inteligencia». Es la inteligencia la que libera, pues gracias a ella "los hombres comprenden ya que no son más instrumentos ciegos de la sociedad; que hay algo que no se cede, ni en virtud de un contrato, ni por la fuerza de una tendencia natural, y que ese algo es la conciencia y la libre expresión de la fuerza individual» ${ }^{65}$. Los saberes y destrezas intelectuales son el vehículo para la independencia y también una base para las jerarquías. El honor que se propone aquí se acerca al que sugiere permanentemente Bunge en sus sentencias y que se funde con el propuesto por muchos miembros de las élites. El honor «es el orgullo de verse encuadernado», es "el orgullo por la obra intelectual realizada» ${ }^{66}$, es, en

62 Ibid., "Una sobra en el espíritu», pp. 183-195.

63 Para una constante rearticulación de los discursos del género y del papel de la mujer en la cultura literaria argentina desde los inicios del gobierno de Juan Manuel de Rosas (1828) hasta 1930: Masiello, F., Op. cit.

${ }^{64}$ Cane, M., Ensayos, Op. cit., «Honor moderno», p. 51.

${ }^{65}$ Ibid., p. 52.

${ }^{66}$ Ibid., p. 6. 
suma, el honor de la gente educada, de aquellos que tienen capital intelectual suficiente -además de económico-, como Miguel Cané. Es una cualidad de la inteligencia y no un saber manual que se expresa con las palabras y termina con las manos.

El «grito de la naturaleza», esa "pasión asistemática contraria al espíritu metodizado" ${ }^{67}$, conjugaba mal con la pretensión de modernidad de la ciudad de Buenos Aires. Para que fuera una ciudad moderna era necesario, entre otras cosas, erradicar la ufalta de dominio sobre sí mismo» posible de leer a partir de la pelea. Pero también desterrar ese "puntilloso sentido del honor personal», para decirlo en palabras de un juez, traducido en una concepción demasiado amplia del honor. Ese honor que abrevaba en habilidades manuales como la destreza física, el saber hacer una determinada tarea, en la fuerza y en el control sexual de las mujeres $^{68}$ debía ser acotado por los derivados del intelecto y acoplarse a la precedencia. La apuesta apuntaba a construir una noción de honor, como dijo Esteban Echeverría, "abstracta» ${ }^{69}$, un orgullo "grande y noble iluminado por la inteligencia»"

\section{CONSIDERACIONES FINALES}

En las últimas décadas del siglo XIX Argentina experimentó una profunda transformación que implicó el pasaje de una serie de regiones fragmentadas y enfrentadas entre sí a un Estado-nación consolidado. Las políticas liberales que inspiraron el proyecto de organización nacional generaron profundos cambios económicos, una modificación en la política social y convirtieron la inmigración masiva en el instrumento central de la transformación.

${ }^{67}$ Ibid., p. 182.

${ }^{68}$ Para el contenido del honor entre los sectores populares nos permitimos remitir a: Gayol, S., «Sociabilité...», Op. cit.

${ }^{69}$ Echeverría, E., "El honor y el sacrificio", en García Velloso (Comp.)., Idioma castellano. Prosa selecta, Angel Estrada, Buenos Aires, s/f.

${ }^{70}$ Cane, M., Op. cit., p. 183. 
El crecimiento demográfico, la concomitante expansión urbana y el desequilibrio entre los liberales y los nuevos sectores populares generaron conflictos en el complejo social argentino. Desde las perspectivas de las élites criollas, Buenos Aires se estaba convirtiendo en una ciudad sitiada, violenta, invadida por un conglomerado anónimo que amenazaba con desterrar los valores tradicionales. El miedo que suscitaban las poblaciones masivas, los efectos nefastos atribuidos a la hibridación y mezcla cultural provocaron la fabricación de una serie de estigmas e imágenes referidas a las masas urbanas.

La alteridad radical negativa, inicialmente aplicada a la población nativa y cuya influencia nefasta nadie se cansaba de resaltar, convivió inicialmente con la alteridad geográfica y racial que, trasplantada a Hispanoamérica, sería clave para empujarla a salir de la oscuridad. Esta alteridad positiva, vista con constante simpatía por echar sus raíces en una raza blanca considerada como superior, fue sometida, en el lapso que va de 1880 a la primera década de nuestro siglo, a revisiones y rearticulaciones permanentes. En el desplazamiento de la degeneración hispano-indígena hacia la degeneración cosmopolita, se impone un retorno al campo, los campesinos y las tradiciones con ellos asociadas. En este viraje, que tenía como propulsor a Buenos Aires, que era el presente, pero también el porvenir hecho presente, nos encontramos con el "otro" próximo que podía ser uno mismo, el "otro" próximo que no podía equipararse con uno mismo y el «otro» racial cada vez más dependiente de criterios sociales, con sus derivados morales, al que se le sumaban consideraciones de género y lingüísticas. La diferencia y la alteridad de la sociedad porteña no se formulaba de manera unívoca y no se leía ni se vivía del mismo modo entre los diferentes actores sociales.

Es la perspectiva del conflicto y la violencia, el temor generado por el aluvión inmigratorio y las confusiones derivadas del ascenso económico las que disparan las estrategias de acercamiento, distanciamiento y reformulación de la alteridad y las alteridades de los valores con que aparecían asociadas. El honor fue un valor común y presente en todas ellas. En una sociedad que no cesaba de transformarse y cuyos criterios de pertenencia «tradicionales» 


\section{LAS ALTERIDADES DE LA MODERNIDAD}

no eran suficientes, el honor devino en una especie de regla a partir de la cual podían ordenarse ciertos comportamientos sociales. Regla susceptible de ser anticipada, noción que buscaba hacer la sociedad más predecible, deberá, no obstante, ser reformulada. Una vez más no se tratará de desterrar el imperio del honor. En la legislación argentina, el honor recibe un tratamiento particular $y$ no se equipara a los restantes delitos, como acontece en otros países. En el Código Penal, el honor es un «bien jurídico tutelado»" es el «bien más preciado y querido del hombre culto» ${ }^{72}$, debiendo contar por ello de la protección de la ley ${ }^{73}$. La ley protege y defiende a quienes han sufrido un "atentado al honor", $y$ son sus ejecutores, no los sujetos individuales, los únicos autorizados a expedirse sobre el tema. La defensa del honor personal debe trasladarse a los hombres de derecho, únicos capaces de actuar "con un criterio jurídico y examinar cada caso a la luz de la psicología positiva ${ }^{74}$. El estudio minucioso del hecho que se juzga inducirá, por un lado, a algunos especialistas a proponer la revisión de la noción misma de «delito pasional», dentro de la cual se encontraba el honor ${ }^{75}, y$, por otro, a una necesidad de acotar el significado

71 Los lineamientos generales fueron señalados por el Proyecto Tejedor, que sigue las huellas del Código español y la exposición de Pacheco. Es aquí donde aparecen las figuras de injuria y calumnia que serán incorporadas en el Código Penal de 1887 con la supresión de la referencia a la publicidad y con la inversión en el orden de legislar las dos figuras. Para un estudio detallado sobre el tratamiento del tema en los distintos proyectos de reforma del Código de 1887: Soler, S., Derecho penal argentino (tomo III), TEA, Buenos Aires 1992.

72 Así se expresan quienes redactaron la «Exposición de Motivos» de 1906. Citado por Soler, S., Op. cit., p. 209.

73 Uno de los motivos inspiradores de la exposición de 1906 fueron algunas resoluciones judiciales en las cuales primó la impunidad. Se quejan los autores de la exposición de motivos de que, cuando se trataba de una imputación genérica, como la de ladrón o estafador, los jueces absolvieron por falta de hecho concreto imputado $y$, en cambio, cuando la imputación era lo suficientemente concreta, se absolviera por falta de prueba positiva del ánimo de ofender.

${ }^{74}$ Gómez, E., "La defensa del honor», en Revista de criminología, Psiquiatría y Medicina legal, Buenos Aires, 1914, T.I, p. 197.

75 Algunos juristas consideraban que muchos individuos, "auténticos criminales", eran puestos en libertad porque sus actos se explicaban y justificaban apelando a la pasión. La recurrencia abusiva a la pasión, la necesidad de diferen- 
SANDRA GAYOL

de la noción de honor. Esta reformulación fue a la par de la necesidad de subsumir el honor indivudual provocador de heridas de muerte en el honor de la nación inculcado en los cuarteles. Este es uno de los objetivos de la Ley Richieri de 1901, que establecerá el servicio militar obligatorio ${ }^{76}$. El honor personal e individual debía subordinarse al honor de la nación y de la institución.

ciarla de la emoción y de recortar y precisar sus alcances derivó en el plano jurídico en una mayor severidad en los actos juzgados por causas de honor.

${ }^{76}$ Para una aproximación sobre el tema en general: Rodríguez, L., Inmigración, nacionalismo y Fuerzas Armadas, Impresora Internacional, México, 1986. 